\title{
Consistency of personality in interactive characters: verbal cues, non-verbal cues, and user characteristics
}

\author{
Katherine Isbister ANd Clifford NAss \\ Communication Department, Stanford University, Stanford, CA 94305-2050, USA. \\ e-mails: isbister@nersange.com,nass@leland.stanford.edu
}

\section{(Received 18 February 1999 and accepted in revised form 19 January 2000)}

\begin{abstract}
This study examined whether people would interpret and respond to verbal (text) and non-verbal cues (posture) of personality in interactive characters just as they interpret cues from a person. In a balanced, between-subjects experiment $(N=40)$, introverted and extroverted participants were randomly paired with one of two types of consistent computer characters: (1) matched participants' personality with both verbal and nonverbal cues or (2) completely mismatched the participant, or one of two types of inconsistent characters: (3) matched with verbal cues but not with non-verbal cues or (4) matched with non-verbal but not with verbal cues. Participants accurately identified the character's personality type in their assessment of its verbal and non-verbal cues. Preference was for consistent characters, regardless of participant personality. Consistent characters also had greater influence over peoples' behavior - interaction with consistent characters led to greater changes in people's answers than interaction with inconsistent characters. Finally, contrary to previous research, participants tended to prefer a character whose personality was complementary, rather than similar, with their own. This study demonstrates the importance of orchestrating the overall set of cues that an interactive computer character presents to the computer user, and emphasizes the need for consistency among these cues.
\end{abstract}

(C) 2000 Academic Press

KEYWORDS: interactive characters; non-verbal cues; personality; consistency.

\section{Introduction}

In recent years, there has been increasing interest in and use of interactive characters in computer interfaces. Interface designers have recognized the value of incorporating characters into the interface for a variety of reasons: to make certain kinds of interactions easier and more natural, such as delegation of tasks (Maes, 1994); to offer computer users intuitive perspectives on data (Oren, Salomon, Kreitman, \& Don, 1990); and to provide more natural assistance [see Isbister and Layton (1995) and Trower (1998) for a review of the roles and functions of interface agents]. Perhaps the most broadly distributed current example is the Microsoft Office 97 interface, which includes animated characters that assist the user in tasks such as help. Interactive animated characters have also begun to be part of the landscape of games and interpersonal communication on-line (e.g. Ultima Online's non-player characters, comic chat and the interactive bartender in Extempo's online Bar). Though these characters can sometimes be very helpful and likable in 
interfaces (Oren, et al., 1990; Reeves \& Nass, 1996), they can also fail to engage users (e.g. the Bob interface, which was not a market success).

As the use of interactive characters in software increases, it is important to develop a systematic understanding of what makes appealing and helpful digital interaction partners. To develop this understanding, we turned to three relevant existing traditions for guidance: user-interface design, traditional media practices for designing appealing characters and psychological principles of human-human interaction that can be applied to interaction with interactive characters.

First, there are some important general principles that already provide guidance in designing usable and engaging interfaces. Experts in usability and interface design often remark that an interface must be designed with clarity and consistency as goals (Norman, 1988; Tognazzini, 1992; Winograd, 1996). When the interface is a GUI, clarity and consistency include things such as using consistent menu names, consistent dialog box layouts and other visual cues that make sense. Consistency also means designing actions that are always performed in the same way, e.g. always having a dialog box with an okay button, or always placing certain controls in certain places in the file system (Tognazzini, 1992; Winograd, 1996; Trower, 1998). This kind of clarity in appearance and behavior sets up consistent expectations in the software user, and allows them to work efficiently and to approach new tasks with the interface without having to expend tremendous mental energy in relearning how the interface will behave.

Consistency also means consistency with a user's expectations (Tognazzini, 1992, pp. 250, 251). People bring their own cultural and physiological "baggage" to interaction with real and digital objects (Norman, 1988). This means that internal consistency is not enough. A good designer should work with the already existing set of expectations that a person brings to his/her interaction with the object, creating intuitive "affordances" (Norman, 1988).

Of course, much of the motivation of introducing characters to the interface was to take advantage of natural human social affordances. "Interface agents draw their strength from the naturalness of the living-organism metaphor in terms of both cognitive accessibility and communication style" (Laurel, 1990, p. 356). Laurel sets up two criteria for judging accessibility in an agent: "if a user can predict what it is likely to do in a given situation on the basis of its character... (and) an agent must be conceived by users as a coherent entity" (p. 363). This important early mandate for consistency and clarity has unfortunately not been followed up with a coherent set of empirically tested principles for creating clear, natural and useful social affordances in our interactive characters.

A second locus of research is the design of characters in traditional media. This research describes what artists and designers already know, from practice, about designing a human-like presence that is appealing and engaging.

Character design is a rich and complex area, with a long history. Practitioners in the arts have developed ways of crafting engaging characters in a variety of media, such as film (Field, 1994), television (Hoffner \& Cantor, 1991), animation (Thomas \& Johnston, 1981), comic books (Eisner, 1985; McCloud, 1993), and written fiction (Lamott, 1994). There are many aspects of character design - as many as there are facets of human behavior and interaction, plus again as many as there are genre constraints for what we expect from mediated characters. However, of the many elements of crafting a successful character, one quality is mentioned with great frequency-personality. Whether it is 
a screenwriting guide or a book about how to make successful animated features, artists seem to agree that developing a clear, consistent, and appealing "personality" is an important part of creating successful characters.

What exactly is 'personality'? Media practitioners have working definitions of personality that they use to try to explain what they do. Thomas and Johnston (1981) discuss how an animated character's personality consists of characteristic attitudes and actions that people learn to associate with that character, as revealed during the story, through the character's motions and conversations, and interaction with other characters. Hoffner and Cantor (1991) say that people use a television character's physical appearance, speech characteristics, and behaviors to determine what the characters' traits are (pp. 68-70). Field (1994) says one develops a movie character's personality by establishing attitudes and behaviors people come to expect from the character. Laurel (1993) says that the traditional Aristotelian understanding of dramatic characters is as "bundles of traits, predispositions, and choices that, when taken together, form coherent entities" ( $\mathrm{p}$. 60). Judging from descriptions taken from all of these traditional media sources, character personality seems to mean predictability in the character's actions and attitudes that people use to understand how the character works within the media they are watching or reading. This corresponds quite nicely to the notion of a consistent interface. In this case, the interface happens to be a character, and the consistent element is its "personality".

This working definition of personality from the arts is also corroborated by the understanding of personality within the field of psychology, the third domain of research on characters in interfaces. The opening definition from a standard psychology textbook is "Personality represents those characteristics of the person that account for consistent patterns of feeling, thinking, and behaving." (Pervin \& John, 1997, p. 4). As in the artists' working knowledge of why a character's personality matters, psychologists have found that personality is a predictor of many important things about a person. For example, one's personality is related to the kinds of social situations one is comfortable in, the jobs one is willing to take and one's style of performing them, how others will choose to interact with one, and a host of other important life activities (Eysenck \& Long, 1986). Personality is something that everyday people recognize and discuss about others, and personality is a valuable piece of information about a person (Pervin \& John, 1997).

Because of its importance in both traditional media and in psychology, we suspected that a consistent and clear personality was important in interactive character design, as well. Operating under a paradigm which suggests that one can directly apply the literature from personality psychology to human-computer interaction (Nass, Moon, Fogg, Reeves \& Dryer, 1995; Reeves \& Nass, 1996), we derived a set of predictions from the psychology literature about what would happen when people interacted with onscreen interactive characters with personality.

We investigated the sorts of cues our characters would need to have to display personality. We were guided by the ways people normally read personality in others. Psychologists have discovered that people use a variety of cues depending upon the situation (Ekman, Friesen, O’Sullivan \& Scherer, 1980). However, people consistently rely a great deal on verbal style and non-verbal cues to guide the determination of personality.

Verbal style includes choice of words and types of sentences and fluidity of speech, as well as how the person refers to another while speaking. For example, an extroverted 
person might use strong, confident words and phrasing, and speak very fluidly, whereas an introverted person might be more hesitant in speech and use less direct and confident phrasing (Jung, 1971).

Non-verbal cues include posture as well as the way that the person moves their body when interacting with others. $\dagger$ For example, an extroverted person uses gestures that are expansive and may approach more readily, whereas an introvert keeps limbs close to the body and avoid approaching (Gallaher, 1992).

In the present study, we used both verbal and non-verbal cues to convey the interactive characters' extroversion or introversion. Surprisingly, no one had yet demonstrated experimentally that people will read personality cues in an interactive character in the same way that they will read them in people, although there is evidence from television research that people apply the same personality traits to TV characters as they do to other people (Reeves and Greenberg, 1977). We predicted that people would successfully label introverted and extroverted verbal and non-verbal cues from interactive characters, just as they identified such cues in previous research with textual cues (Moon \& Nass, 1996).

Using two different sets of cues allowed us to examine the effects of personality consistency in our characters. As was mentioned above, both user-interface designers and traditional character designers warn against inconsistency. Guidelines for creating characters often include a caveat that everything a character does should convey the same general impression about the character to the viewer (Thomas \& Johnston, 1981; Field, 1994). These caveats are needed because it is easy for inconsistencies to creep in during the development process. This is especially the case for complex character creation involving a large team of people, as is often found in the development of interactive characters.

Psychologists also point out the benefits of consistency. Consistency in others allows people to predict what will happen when they engage with them (Fiske \& Taylor, 1991), makes it easier to remember a person accurately (Cantor \& Mischel, 1979), and generally lightens cognitive load (Fiske \& Taylor, 1991). There is literature which suggests that adults use mismatched verbal and gestural cues in children to help determine the child's knowledge state to facilitate learning (Goldin-Meadow, Alibali \& Church, 1993). In addition, studies that looked at how people detect deception have found that people turn to non-verbal cues to see if they are inconsistent with the verbal ones (Ekman \& Friesen, 1974; Ekman, et al., 1980). Finally, researchers have shown that although people are not necessarily aware of mismatches between verbal and gestural cues, they integrate both of these sets of cues into their understanding of what was said (Cassell et al., 1998). These results taken together suggest that discrepancy among cues is something that will be noticed, and that may be a critical problem in other people.t

\footnotetext{
$\dagger$ Non-verbal cues from people are not limited to those that reveal their personality style. People also convey important conversational information through their gestures. Most notable in this regard is Justine Cassell's research program, which investigates the importance and automation of these sorts of communicative gestures in interactive characters (Cassell, McNeill \& McCullough, 1998; Cassell \& Thorisson, 2000; Cassell \& Vilhjalmsson, 1999).

¥It is important to note that the form of inconsistency investigated in this experiment is simultaneous, conflicting cues. There are also research findings concerning sequential inconsistency in behavior, which are not discussed here. For further information about this literature, as well as results of a follow-up study to the one presently under discussion, see Isbister (1998).
} 
The story of personality and how it affects interpersonal interaction goes beyond clarity and consistency. To have an accurate picture of how personality affects interpersonal interaction, one must take individual differences in preference into account. We included some aspects of this literature in our experiment design as well. Studies of interpersonal psychology have shown that people tend to select and prefer others based on the match or mismatch to their own personality. There are two competing hypotheses in this literature: the similarity-attraction hypothesis and the complementarity principle.

Similarity-attraction holds that people seek out others who are similar to themselves, and prefer to interact with similar people. Thus, this hypothesis predicts that people will prefer those with personalities similar to their own (Byrne, 1969; Blankenship, Hnat, Hess \& Brown, 1984; for a review, see Nass et al., 1995). The similarity-attraction hypothesis has held true in situations ranging from preference for newly met people (Griffit, 1966; Byrne \& Griffit, 1969) to success in long-term relationships such as marriage (Richard, Wakefield \& Lewak, 1990).

Complementarity holds that people will tend to behave in complementary ways in their interpersonal interactions, and will seek out others that elicit complementary behavior from them. Complementarity research began with the work of Leary and Sullivan in the 1950s (Sullivan, 1953; Leary, 1957). The idea is that people tend to seek out a balance in the power relations in an interaction: one person will be more dominant than the other, otherwise there is imbalance and tension. Also, people seek out a balance in the amount of friendliness in an interaction: one person gauges the level of friendliness of the other, and responds in kind. Several extensive reviews of complementarity research have been written, although the overall picture is mixed (for a more complete comparison of similarity-attraction and complementarity, see Nass et al., 1995).

Though both similarity-attraction and complementarity have experimental confirmation in the psychological literature, in the human-computer interaction literature, only similarity-attraction has compelling experimental support (Moon \& Nass, 1996; Nass et al., 1995). The Nass et al. (1995) experiment matched dominant or submissive individuals (as discerned from pretests) with dominant or submissive computers. Computer personality was created by manipulating the computer's verbal style, confidence level, name, and choice of font. Participants did in fact correctly identify dominant and submissive computers, and preferred interacting with a computer similar to themselves. Matched participants found the interaction more fun, more useful and more satisfying. Later studies (e.g. Moon \& Nass, 1996) confirmed similarity-attraction in the case of interaction with a text-based computer. Because of these human-computer findings, we predicted a similarity-attraction effect in our study.

The literature on how personalities interact throws into question the assumption of the $a$ priori desirability of consistency if there can only be a single character for all users. Although the human-human literature suggests that consistency is more important than compromising by having verbal cues manifesting one personality and non-verbal cues manifesting the opposite personality, it is possible that when it comes to interactive characters, half a loaf is better than none. This could occur because, in contrast to human-human interaction, when observing characters, the matching modality is more (similarity-attraction) or less (complementarity) influential than the mismatched modality. Our final goal for this experiment was to determine whether consistency or inconsist ency is optimal for interactive characters. 
To summarize, there were four issues to be addressed in this study: (1) to replicate the finding that users can recognize personality in verbal cues of interactive characters, (2) to demonstrate that users can recognize personality in non-verbal cues, (3) to determine whether inconsistent characters are universally disliked (consistency theory) or perceived as better than inappropriately matched consistent characters; and (4) to determine, for computer characters, if people prefer to work with others that are similar to themselves.

To address these issues, and to generate principles for designing appealing and effective interactive characters, we created a balanced, between-subjects design in which introverted or extroverted individuals were randomly assigned to one of the four conditions: (a) wholly matching character (verbal and non-verbal cues were consistent and matches the user); (b) wholly mismatched character (verbal and non-verbal cues were consistent but were opposite the user); (c) matching verbal and mismatching nonverbal; and (d) mismatching verbal, matching nonverbal. Examining the two main effects (verbal personality and non-verbal personality) allows us to address issues (1) and (2). A comparison of the (a) and (b) conditions vs. the (c) and (d) conditions will answer whether consistency is desirable [issue (3)]. A comparison of conditions (a) and (b) provides a critical test of similarity-attraction vs. complementarity [issue (4)].

\section{Method}

\subsection{PARTICIPANTS}

Participants were 40 students from two West Coast universities, all enrolled in communication classes. Students received course credit for their participation. Students from the two universities were balanced across conditions in the experiment.

Several weeks prior to the study, students at each university completed a portion of the Myers-Briggs personality inventory (see Murray, 1990 for a review), as well as a portion of the Wiggins interpersonal adjective set (Wiggins, 1979), as part of a packet of questionnaires administered to the entire class. Both subsets of these measures are designed to evaluate the ratee's level of extroversion or introversion. In the Myers-Briggs inventory, there is a bipolar scale along which a participant is placed on their level of introversion or extroversion: a high score indicates introversion and a low score indicates extroversion. The Wiggins adjectives reflect two separate scales, one each for extroversion and introversion. Students who fell above the class median on the Myers-Briggs (higher than 4 out of a possible score of 9) and on the Wiggins introversion scale (higher than 27 out of a possible score of 54) were classified as introverted; students who fell below the class median on the Myers-Briggs and above it on the Wiggins extroversion scale (higher than 38 out of a possible score of 54) were classified as extroverted.

Twenty students from the extroverted group and 20 students from the introverted group were asked to participate in the study. Participants were simply told that they would be participating in a study examining how people work with computer characters to accomplish a task. All participants signed informed consent forms, were debriefed at the end of the experimental session, and were awarded class credit for their participation in the experiment. 


\subsection{PROCEDURE}

Extroverted and introverted participants were randomly assigned to one of four conditions in a $2 \times 2$ balanced, between-subjects design: matching (the participant) or mismatching verbal cues by matching or mismatching non-verbal cues.

Upon arrival, the participant was asked to complete the Desert Survival Problem (DSP) (Lafferty \& Eady, 1974) using pencil and paper. The DSP is a problem-solving task that has been used in a variety of studies involving interpersonal interaction (Dryer, 1993). It asks participants to rank a series of items (in this case, 12 items: compress kit, book, raincoat, flashlight, vodka, parachute, water, mirror, jack knife, magnetic compass, salt tablets and air map), according to the participants' perception of their importance in a desert survival situation.

After finishing this initial ranking, the participant was introduced to an on-screen computer character. The experimenter explained that the participant would have the opportunity to exchange information about each of the 12 desert survival items with the computer character. In addition, after completing the interaction with the character, the participant would have the opportunity to change his or her initial ranking.

The onscreen character was in a format similar to comic books: the figure was a still image in each turn, with a word-balloon with text in it which represented its own "voice" (see Figure 1). The character stayed in one place on each screen, creating the impression that one was working through an interaction with a comic-book-like character. Participants typed their own words into their own text word-balloon, which also stayed onscreen in the same place throughout the interaction.

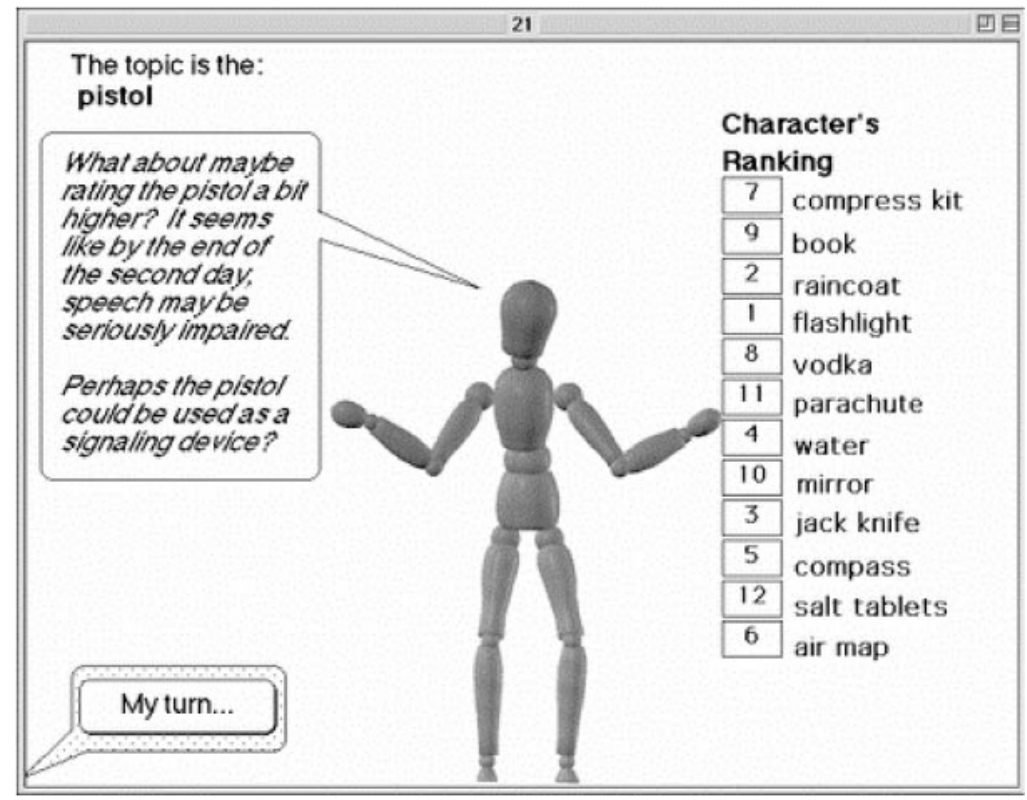

FIGURE 1. Sample of experiment interface (This shows the sample item screen - the pistol was the practice item.). The character is displaying an extroverted posture and introverted verbal style. 
At this point, the computer setting for the task was explained to the participant. The participant was shown how to press "ready" buttons after reading the character's information, and how to enter his or her own information in response.

After a single practice session, the experimenter left the room. The participant was left alone to exchange information with the computer character about each of the 12 desert survival items.

After the interaction was complete, the participant was given an opportunity to make a final ranking of the desert survival items, on paper. Subsequently, the participant was given a set of questionnaires to fill out. The questionnaires asked the participant for his or her assessment of both the computer character and the interaction itself.

Upon completing the questionnaire, the participant was debriefed, thanked and asked not to discuss the experiment with other classmates until the study was completed.

\subsection{MANIPULATION}

Each participant interacted with a computer character with one of four possible sets of personality cues: extroverted in both verbal and non-verbal behavior; introverted in both verbal and non-verbal behavior; extroverted in verbal but introverted in non-verbal behavior; or introverted in verbal but extroverted in non-verbal behavior.

Verbal extroversion or introversion was operationalized by manipulating the phrasing of the text displayed in the character's word balloons during the interaction. The extroverted computer character used strong and friendly language expressed in the form of confident assertions. This manipulation is consistent with the theoretical definition of extroversion as being the tendency to be assertive, outgoing and friendly. The introverted computer character used weaker language expressed in the form of questions and suggestions. This manipulation is consistent with the theoretical definition of introversion as behavior that indicates less ease in socializing, and less assertiveness.

For example, the extroverted character would display the following text: "Friend, I'd say the pistol should definitely be rated higher. By the end of the second day, speech will be impaired and the pistol will be an important signaling device." In contrast, the introverted computer character would display the following text: "What about maybe rating the pistol a bit higher? It seems like by the end of the second day, speech may be seriously impaired. Perhaps the pistol could be used as a signaling device?"

All text for this manipulation was pre-tested to confirm that it was achieving the desired impression in respondents. Raters were randomly assigned to rank either the introverted or extroverted transcript of statements made by the character on the same Myers-Briggs and Wiggins indices that were used by participants. Ratings confirmed that the character statements were being read as expected.

Non-verbal extroversion or introversion was operationalized by manipulating the postures of the computer characters. The extroverted character body had poses with its limbs spread wide from its body, and some postures made the character seem to have moved closer to the participant. This is consistent with the literature on non-verbal cues of extroversion, which indicate that extroverts tend to make wider movements and to more freely approach others in space. The introverted character body had poses with its limbs closer in to its body, and did not ever appear to approach the participant. This is consistent with the literature on non-verbal cues of introversion which indicate that 


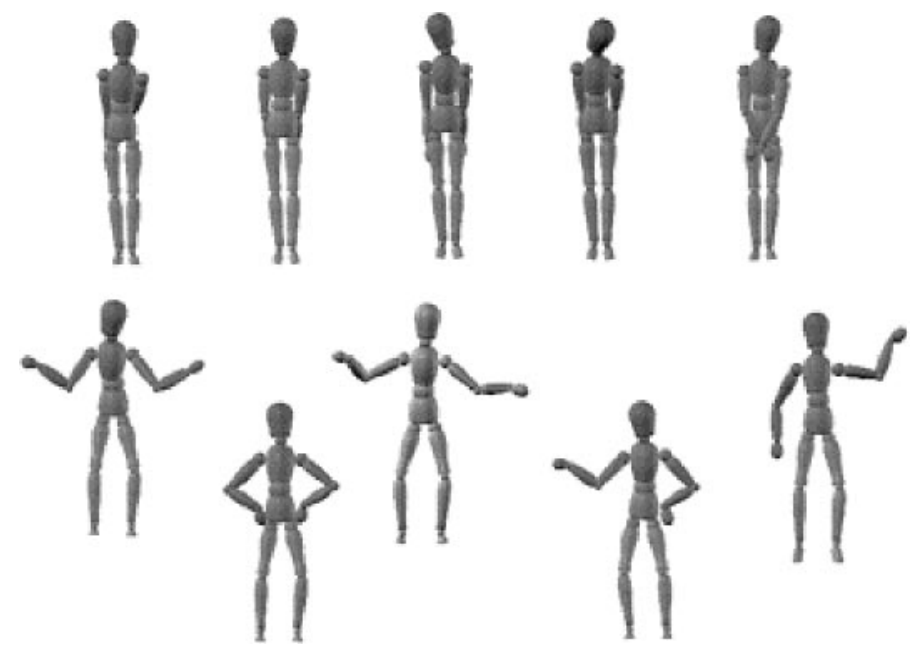

FIGURE 2. Sample of character body postures (Top row has examples of introverted postures; bottom row has examples of extroverted postures.)

introverts tend to keep their limbs closer to their bodies, to gesture less freely, and to avoid approaching others in space. The character itself was a simple stick figure, which allowed us to avoid possible effects of other cues of personality and personal qualities that arise from things like age, clothing, facial appearance or gender (see Figure 2).

As with the verbal cues, the non-verbal cues were pre-tested to confirm that they were being read properly. The character poses were placed on the World Wide Web. Raters were invited to view all poses in one set, and then rank the character on the same scales used by the participants in assessing introversion or extroversion. As with the verbal cues, ratings confirmed that the character poses were being read as expected.

It is essential to realize that the fundamental information conveyed by the computer character was not manipulated; that is, in all four conditions the computer character conveyed the same type and amount of information about the items being discussed in the task. Only the style of communication was manipulated.

It is also important to note that all responses were pre-programmed. There was no natural language processing or artificial intelligence employed. To create a smooth interaction, the character always went first in discussing an item, then the participant responded with his or her own information about an item.

\subsection{MEASURES}

The dependent variables were measured using a set of paper-and-pencil questionnaires.

The first set of questions asked, "For each word below, please indicate how well it describes your interaction with the character on the computer. Note that you are evaluating the actual interaction, not the character itself." This was followed by a list of adjectives (e.g. "fun", "interesting", "useful"), each of which had a 9-point Likert scale that ranged from "Describes very poorly" to "Describes very well". 
The second set of questions also used 9-point Likert scales, and were aimed at allowing participants to rank their satisfaction with the character and its perceived value.

The third set of questions asked "For each word below, please indicate how well it describes the character that you just worked with. Note that you are evaluating the character now, NOT the interaction." This was followed by a list of adjectives (e.g. "assertive", "friendly", "bashful"), each of which had a 9-point Likert scale that ranged from "Describes very poorly" to "Describes very well". This list of adjectives included all those used in the Wiggins introversion and extroversion scales.

Participants then rated the character's body language and verbal style separately on the Wiggins scales.

\subsection{INDEX CONSTRUCTION}

Based on factor analysis, four indices were created from the questionnaire items.

Fun was an index of four adjective items used to characterize the interaction: enjoyable, exciting, fun and satisfying. The index was very reliable (Cronbach's $\alpha=0.90)$.

Liking was an index of two items from the character question section of the questionnaire. These items were: "would you enjoy working with this character in another experiment" and "how much did you like this character". The index was very reliable $(r=0.82)$.

Usefulness of the Interaction was an index of two items used to characterize the interaction: helpful and useful. The index was very reliable $(r=0.91)$.

Usefulness of Character was an index comprised of three items from the character question section of the questionnaire: "how much did the character improve your ranking of the items", "how much did you learn from interacting with this character", and "how helpful did you find this character". This index was also very reliable $(\alpha=0.89)$.

To assess the perception of the character's personality, we created an index of the Wiggins introversion and extroversion scales for the verbal and non-verbal cues respectively to reflect a general extroverted vs. introverted assessment (hereafter referred to as the "extroverted" dimension).

\section{Results}

Consistent with previous research, participants accurately identified the extroverted language as significantly more extroverted than the introverted language, $F(1,38)=$ $5.26, p<0.05$ (see Figure 3). (All figures have standardized the indices to reflect a 9-point Likert scale.) Extending these findings to non-verbal cues, the extroverted postures were perceived as significantly more extroverted than the introverted postures, $F(1$, 38) $=8.90, p<0.01$.

Focusing on the two consistent conditions, we find evidence for complementarity rather than similarity-attraction. Specifically, the computer character was perceived as significantly more fun, $F(1,18)=4.3, p<0.05$ (see Figure 4), and more likable, $F(1,18)=4.2, p<0.05$, (see Figure 4) when its personality was complementary to that of the participant. Although the means were in the same direction, participants perceived 


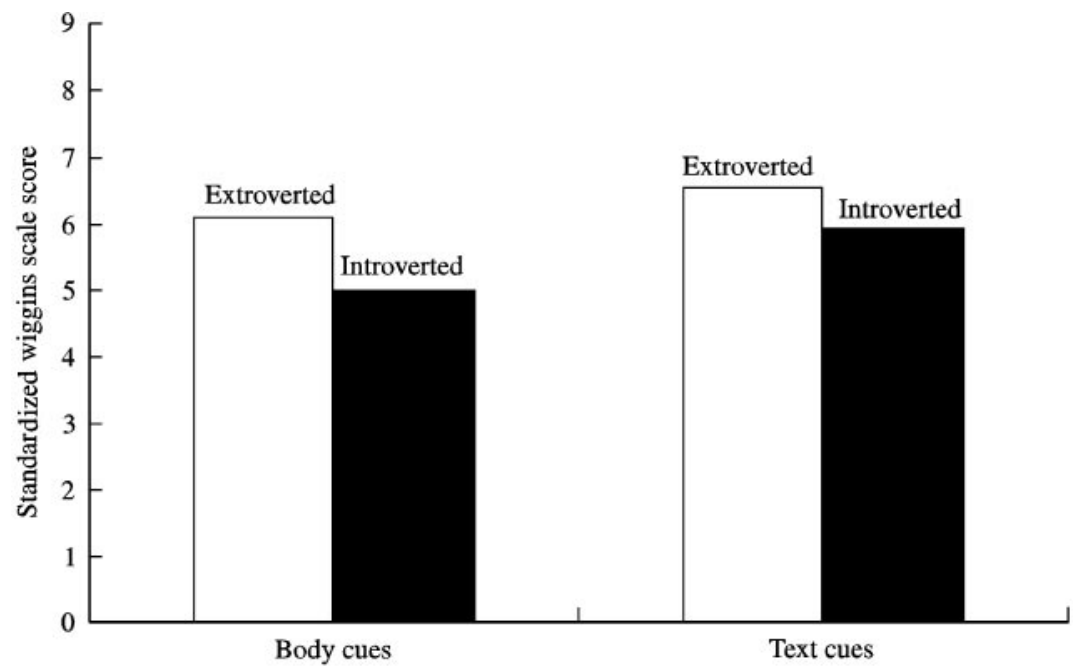

FIGURE 3. Effects of body and text cues on ranking of body and text on Wiggins introversion/extroversion measure.

neither the computer character nor the interaction as significantly more useful when complementary or similar $(p>0.50)$

Text and body cue effects on participants' rankings of the characters showed a consistent interaction on all four indices, giving support to the consistency model of how we read mixed cues. We would have expected to see only main effects if participants were evaluating both cue sets separately and coming to an additive assessment, rather than judging based on a blended whole picture of all cues.

For Fun, there was an interaction that approached significance between body and text match to participant, $F(1,38)=3.50, p<0.07$, indicating a preference for consistency. The main effect for body match to participant, $F(1,38)=5.47, p<0.03$, is consistent with complementarity (see Figure 5).

On Liking, there was a significant interaction between body and text match to participant, $F(1,38)=4.21, p<0.05$. Preference for complementarity in postures approached significance, $F(1,38)=3.79, p<0.06$ (see Figure 5).

Usefulness of Interaction showed a significant interaction between body and text match to participant, $F(1,38)=6.87, p<0.02$ (see Figure 5). There were no main effects for text or body.

Usefulness of Character also showed an interaction that approached significance between body and text match to participant, $F(1,38)=3.29, p<0.08$ (see Figure 5). There were no main effects for text or body.

Finally, in $t$-tests comparing means on all four indices for consistent-cue characters vs. inconsistent-cue characters, a clear pattern emerged: in each case, consistent characters were ranked significantly more highly than inconsistent characters, lending support to preference for consistency. Results for each index were as follows: for Fun, $t(39)=1.79$, $p<0.05$; for Liking, $t(39)=2.00, p<0.03$; for Usefulness of Interaction, $t(39)=2.57$, $p<0.01$; and for Usefulness of Character, $t(39)=1.86, p<0.04$ (see Figure 6). 


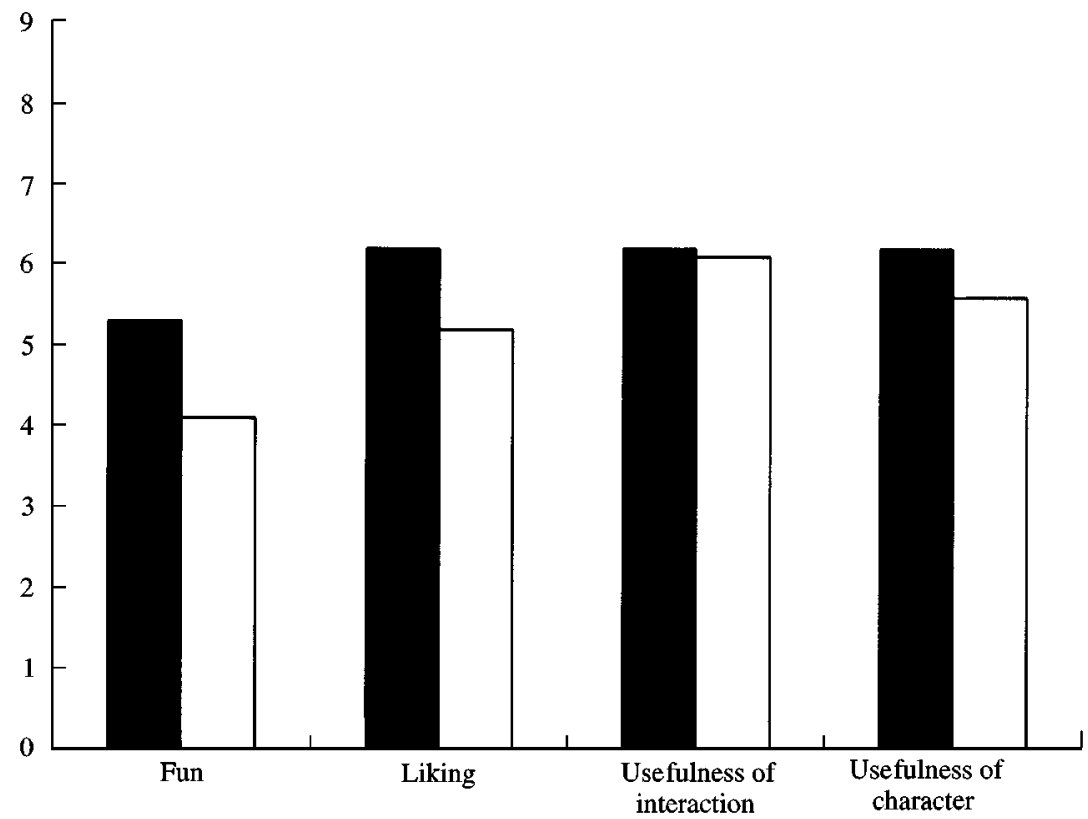

FIGURE 4. Effects of character-participant personality match on fun, liking, usefulness of interaction, and usefulness of character. ( $\square$ ) complementary personality; $(\square)$, similar personality.

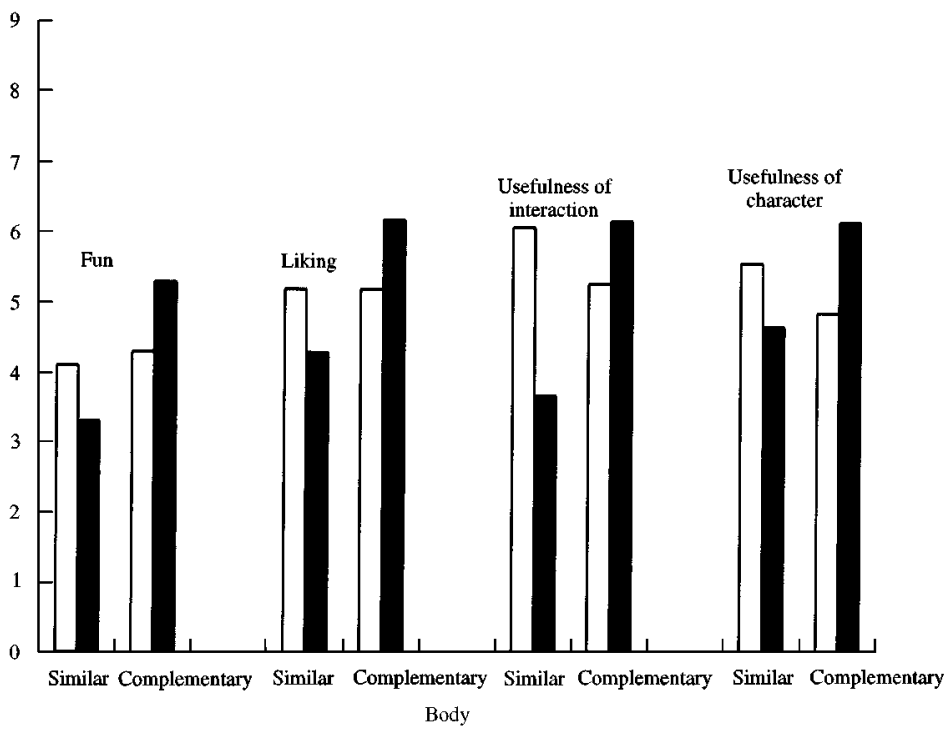

FIGURE 5. Effects of character body and text cue match to participant on fun, liking, usefulness of interaction, and usefulness of character. $(\square)$ similar text; $(\mathbf{\square})$, complementary text. 


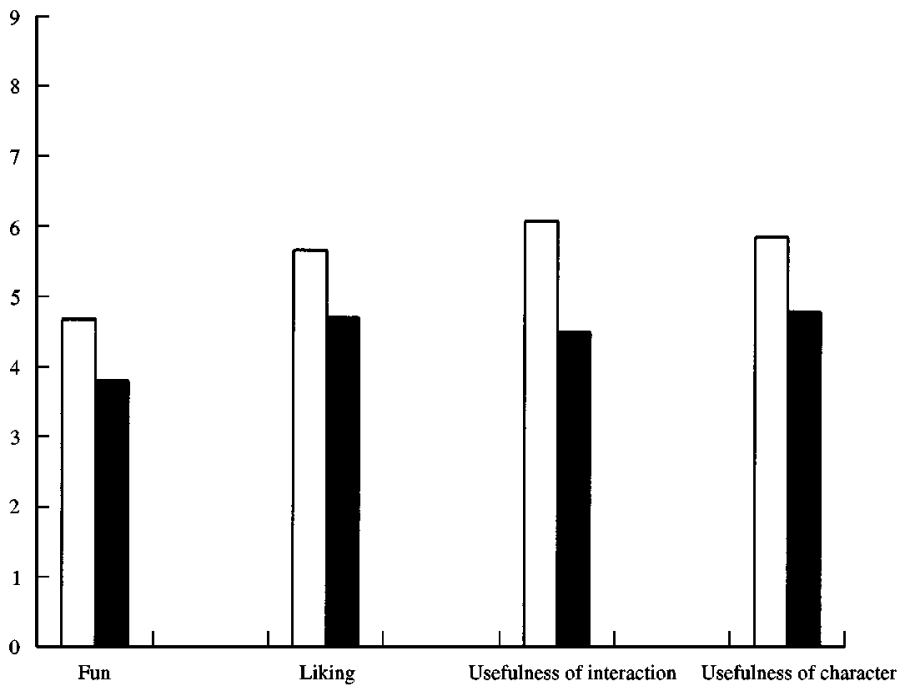

FIGURE 6. Effects of cue consistency on fun, liking, usefulness of interaction, and usefulness of character. ( $\square$ ), consistent cues; (ם), inconsistent cues.

Additional support for the preference for consistency was found by examining change in the participants' rankings of the items in the Desert Survival item list. Comparing initial rankings to final rankings, a significantly larger change in rankings was found in the consistent character conditions, $F(1,38)=7.9, p<0.01$, suggesting that the information from the consistent character was more compelling (see Figure 7).

\section{Discussion}

By showing that people's human-human social expectations affected their evaluation of interactive characters, and their own behavior, this research introduces an approach to generating useful and empirically testable interactive character design principles. HCI practitioners can use human psychology and traditional character design practices to shape guidelines for creating interactive characters.

In this study, people labeled gestures and verbal styles in interactive characters the same way they would label postures and verbal styles in other people. And, just as is the case in interaction with other people and traditional GUIs, participants preferred consistency in the characters they interacted with, and used all the cues from the characters to form an overall impression by which the character was judged. This means that character developers should pay close attention not only to the words, but also to the postures of their characters, and ensure that they send the same messages to users.

This study demonstrated that the compromise model of how personality cues work in interactive characters is not appropriate, confirming the working knowledge of character designers in other media, and highlighting the importance of coordinated development efforts in crafting consistent interactive characters. 


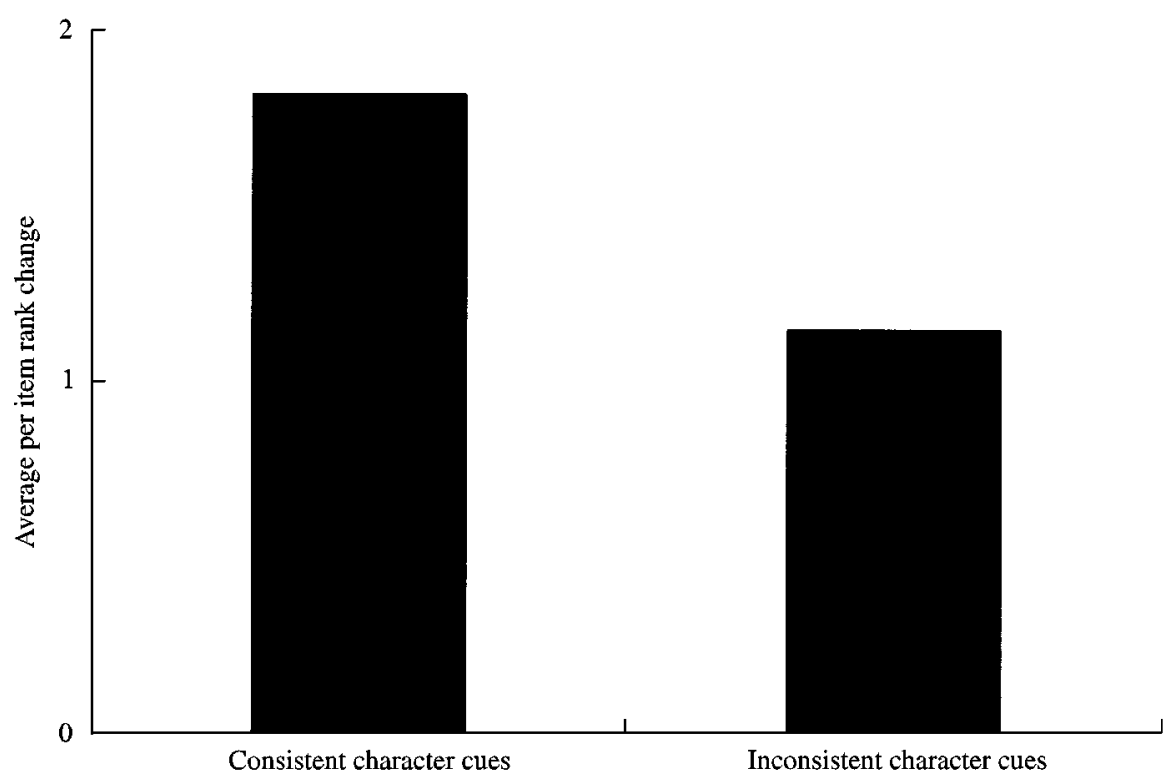

FIGURE 7. Effects of character cue consistency on change in participants' rankings of items.

The rating behavior in this study highlights the importance of cue consistency. Inconsistent character cues may undermine a character's relationship with the computer user, not only leading to less liking, but also to less influence. Designers of characters that are meant to play a tutoring, guiding or shopping role may want to be especially careful about consistency.

The preference for consistency in characters found in this study held true regardless of the character's similarity to or difference from the participant, both in liking and persuasiveness. This result has implications for the design of computer characters, suggesting that it may be more important that the character is consistent than that it complement or match the individual on a particular dimension. Prior work already has demonstrated that inconsistent text-based interfaces are hard to trust (Muir, 1987; Moray, Hiskes, Lee \& Muir, 1995).

The current study examined consistency between verbal and non-verbal cues that were being sent at the same time. There are certainly other important types of inconsistency. For example, it might be valuable to consider inconsistencies that manifest over time - what happens when a character has a personality shift during the course of interaction? This is a plausible situation, given today's reuse and extension of interactive characters, both within a single operating system and also on the World Wide Web. How do people resolve inconsistencies in a character's behavior on two different web sites, when it is the "same" character? How does this affect their liking for the character, and its perceived usefulness? [See Isbister (1998) for a review of literature on inconsistency over time, as well as results of a study which examines this sort of inconsistency.]

Posture and language are just two possible manifestations of personality. Given the present results, the concern with consistency should be extended to all other aspects of 
representations that suggest personality, including morphology, such as body size, shape and general appearance; voice qualities, such as speech rate, pitch range and amplitude; motions and gestures, etc.

Contrary to previous human-computer interaction literature (Reeves \& Nass, 1996), this study showed that people preferred a character that was complementary to them, vs. one that was similar. This finding complicates our understanding of preference for interactive characters. One provocative explanation for this seeming contradiction is a potential parallel in the HCI and the psychology literature. In the HCI context, prior research used only textual manifestations of personality, while the present study used a character. Similarly, when participants are presented with textual descriptions of people (the more common methodology), one finds similarity-attraction, while participants who actually interact with others tend to exhibit complementarity effects. This may suggest that characters increase social presence and the sense of a direct interaction. Future research should certainly pursue this possibility.

A second, less interesting, explanation is that the present study manifested extroversion and introversion, while previous studies manifested dominance and submissiveness. Both scales are highly valid and quite related, but represent the taxonomies of two different subgroups of psychologists and their research. Interpersonal studies tend to use dominance-submissiveness as an axis rather than extroversion-introversion. They locate the extroversion-introversion trait at the diagonals of the space formed by their two axes; that is, extroversion is friendly and dominant; introversion is unfriendly and submissive (Wiggins, 1979). Both interpersonal and trait psychologists have noted the similarities in the dimensions (McCrae \& Costa, 1989; Trapnell \& Wiggins, 1990), and proposed that they be folded together to afford greater parsimony and completeness in assessing individuals' traits. The extroversion-introversion dimension was chosen for this study because it is the salient dimension in the non-verbal cue research. To eliminate the hypothesis that this choice resulted in the complementarity finding, it would be necessary to conduct a follow-up study, crafting characters that mapped to the dominance-submissiveness dimension. For interface designers, both scales may be of value, depending upon the purpose of the interface, the task and the role that the user must play. When designing for initial engagement with the interface and ongoing general social interaction, the introversion-extroversion scale may be more relevant; when designing interactions in which joint control and control shifts become important to manage, dominance-submissiveness may turn out to be a more important factor in user experience.

Overall, this study is an important step toward building shared tools and standards for crafting useful and likable interactive interface characters. As the use of these characters in software increases, it is essential that designers of these characters work with people's natural interpretation strategies to build the right affordances into characters, and that they bring the same rigor to crafting these new interface tools as they already bring to designing quality GUIs.

\section{References}

Blankenship, V., Hnat, S. M., Hess, T. G. \& Brown, D. R. (1984). Reciprocal interaction and similarity of personality attributes. Journal of Social and Personal Relationships, 1, 415-432. 
Byrne, D. (1969). Attitudes and attraction. In L. Berkowitz, Ed. Advances in Experimental Social Psychology, vol. 4. Orlando, FL: Academic Press.

BYrne, D. \& GRIFFIT, W. (1969). Similarity and awareness of similarity of personality characteristic determinants of attraction. Journal of Experimental Research in Personality, 3, 179-186.

CAntor, N. \& Mischel, W. (1979). Prototypes in person perception. Advances in Experimental Social Psychology, 12, 3-52.

Cassell, J., McNeill, D. \& McCullough, K. E. (1998). Speech-gesture mismatches: evidence for one underlying representation of linguistic and nonlinguistic information. Pragmatics and Cognition, 6.

CAssell, J. \& Thorisson, K. (2000). The power of a nod and a glance: envelope vs. emotional feedback in animated conversational agents. Journal of Applied Artificial Intelligence. (in press).

Cassell, J. \& Vilhjalmsson, H. (1999). Fully embodied conversational avatars: making communicative behaviors autonomous. Autonomous Agents and Multi-Agent Systems, 2.

DRYER, D. C. (1993). Interpersonal goals and satisfaction with interactions. Doctoral Dissertation, Stanford University.

EISNER, W. (1985). Comics and Sequential Art. Tamarac, FL: Poorhouse Press.

Ekman, P. \& Friesen, W. V. (1974). Detecting deception from the body or face. Journal of Personality and Social Psychology, 29, 288-298.

EkMan, P., Friesen, W. V., O'Sullivan, M. \& Scherer, K. (1980). Relative importance of face, body, and speech in judgments of personality and affect. Journal of Personality and Social Psychology, 38, 270-277.

EYSENCK, S. B. G. \& LONG, F. Y. (1986). A cross-cultural comparison of personality in adults and children: Singapore and England. Journal of Personality and Social Psychology, 50, 124-130.

FIELD, S. (1994). Screenplay: The Foundations of Screenwriting. New York: Bantam Doubleday Dell.

Fiske, S. T. \& TAYlor, S. E. (1991). Social Cognition. New York: McGraw-Hill, Inc.

GALlAHER, P. E. (1992). Individual differences in nonverbal behavior: dimensions of style. Journal of Personality and Social Psychology, 63, 133-145.

Goldin-Meadow, S., Alibali, M. \& Church, R. B. (1993). Transitions in concept acquisition: using the hands to read the mind. Psychological Review, 100, 279-297.

GRIFFIT, W. R. (1966). Interpersonal attraction as a function of self-concept and personality similarity-dissimilarity. Journal of Personality and Social Psychology, 4, 581-584.

HoffNer, C. \& CANTOR, J. (1991). Perceiving and responding to mass media characters. In J. Bryant \& D. Zillmann, Eds. Responding to the Screen: Reception and Reaction Processes. Hillsdale, NJ: Erlbaum.

ISBISTER, K. (1998). Reading personality in onscreen interactive characters: an examination of social psychological principles of consistency, personality match, and situational attribution applied to interaction with characters. Doctoral Dissertation, Stanford University.

Isbister, K. \& LAYTON, T. (1995). Agents: what (or who) are they? In J. NiElSEN, Ed. Advances in Human-Computer Interaction, vol. 5, pp. 67-86. Norwood, NJ: Ablex Publishing Corporation.

JunG, C. G. (1971). Psychological Types. Princeton, NJ: Princeton University Press.

LAfFerTy, J. C. \& EADY, P. M. (1974). The Desert Survival Problem. Plymouth, MI: Experimental Learning Methods.

Lamott, A. (1994). Bird by Bird: Some Instructions on Writing and Life. New York: Pantheon Books.

LAUREL, B. (1990). Interface agents: metaphors with character. In The Art of Human Computer Interface Design, pp. 355-365. B. LAUREL, Ed. Reading, MA: Addison-Wesley Publishing Company.

LAUREL, B. (1993). Computers as Theater. Reading, MA: Addison-Wesley.

LeAry, T. F. (1957). Interpersonal Diagnosis of Personality. New York: Ronald Press.

MAES, P. (1994). Agents that reduce work and information overload. Communications of the ACM, 37.

MCCloud, S. (1993). Understanding Comics: The Invisible Art. New York: Harper Collins. 
MCCrae, R. R. \& John, O. P. (1992). An introduction to the five-factor model and its applications. Journal of Personality, 60, 175-215.

Moon, Y. \& NASS, C. (1996). How "real" are computer personalities? Psychological responses to personality types in human-computer interaction. Communication Research, 23, 651-674.

Moray, N., Hiskes, D., LeE, J. \& Muir, B. (1995). Trust and human intervention in automated systems. In J.-M. Hoc, P. C. CaCCiabue \& E. Hollnagel, Eds. Expertise and Technology: Cognition and Human-Computer Interaction, NJ: Lawrence Erlbaum.

Muir, B. M. (1987). Trust between humans and machines, and the design of decision systems. International Journal of Man-Machine Studies, 27, 527-539.

Murray, J. B. (1990). Review of research on the Myers-Briggs type indicator. Perceptual and Motor Skills, 70, 1187-1202.

Nass, C., Moon, Y., FogG, B. J., Reeves, B. \& Dryer, D. C. (1995). Can computer personalities be human personalities? International Journal of Human-Computer Studies, 43, 223-239.

Norman, D. (1988). The Design of Everyday Things. New York: Currency Doubleday.

Oren, T., Salomon, G., Kreitman, K., \& Don, A. (1990). Guides: characterizing the Interface. In B. LAUREL Ed. The Art of Human-Computer Interface Design. Reading, MA: Addison-Wesley.

Pervin, L. A., \& John, O. P., Eds. (1997). Personality Theory and Research. New York: Wiley.

Reeves, B. \& GreenberG, B. (1977). Children's perception of television characters, Human Communication Research, 3, 113-117.

Reeves, B. \& NAss, C. (1996). The Media Equation: How People Treat Computers, Television, and New Media Like Real People and Places. Stanford, CA: CSLI Publications.

RICHARD, L. S., WAKEFIELD, J. A. \& LEWAK, R. (1990). Similarity of personality variables as predictors of marital satisfaction: a Minnesota multiphasic personality Inventory (MMPI) item analysis. Personality and Individual Differences, 11, 39-43.

Sullivan, H. S. (1953). The Interpersonal Theory of Psychiatry. New York: Norton.

Thomas, F. \& Johnston, O. (1981). The Illusion of Life: Disney Animation. New York: Hyperion.

TognAZZINI, B. (1992). Tog on Interface. Reading, MA: Addison-Wesley Publishing Company, Inc.

Trapnell, P. D. \& Wiggins, J. S. (1990). Extension of the interpersonal adjective scales to include the big five dimensions of personality. Journal of Personality and Social Psychology, 59, 781-790.

Trower, T. (1998). Developing for Microsoft Agent. Troy, MI: Microsoft Press.

WigGins, J. S. (1979). A psychological taxonomy of trait-descriptive terms: the interpersonal domain. Journal of Personality and Social Psychology, 37, 395-412.

Winograd, T. (1996). Profile: Macintosh human interface guidelines. In T. WinOgrad, Ed. Bringing Design to Software, pp. 81-85. New York: ACM Press.

Paper accepted for publication by Associate Editor, Dr I. Witten 